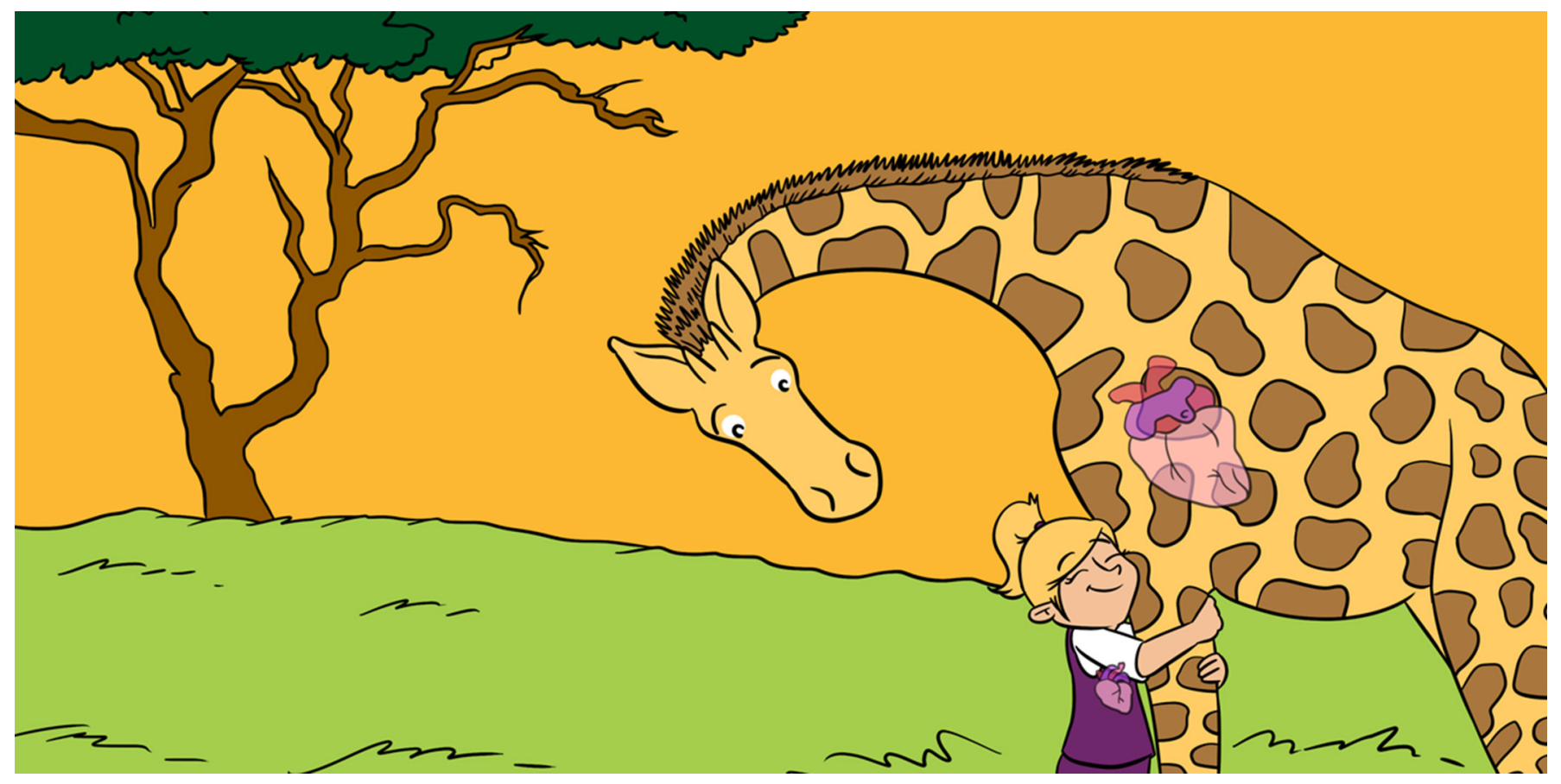

\title{
HEARTS, AND THE HEARTLESS, IN THE ANIMAL KINGDOM
}

\section{Aziza Alibhai ${ }^{1}$, Kelly Stanford ${ }^{2}$, Sharon Rutland ${ }^{3}$ and Catrin Sian Rutland ${ }^{1 *}$ \\ ${ }^{1}$ School of Veterinary Medicine and Science, University of Nottingham, Nottingham, United Kingdom \\ ${ }^{2}$ Energy and Environment Institute, University of Hull, Kingston upon Hull, United Kingdom \\ ${ }^{3}$ Teacher and Independent Copy-Editor, Derby, United Kingdom}

YOUNG REVIEWERS:

BRUNA

AGE: 15

NÍCOLAS

AGE: 11
We all take our hearts for granted: the fascinating organ inside everyone that beats continuously to keep blood pumping through our bodies. Blood flow ensures that oxygen, nutrients from food, hormones, and waste products get to the correct cells. The heart is essential for keeping humans and most animals alive. Hearts are even more interesting when we examine what they do, how they look, how they work, and the similarities and differences in the hearts of species across the planet. Is a giraffe heart similar to a human heart? Which animal survives despite having no heart? Can a heart really beat over 1,500 times a minute? From dinosaurs to insects, humans to dogs, this paper looks at what is really happening on the inside, exploring the world of heart anatomy. 


\section{CEPHALOPODS}

Animals without backbones, including squids, octopi, and nautiluses.

Cephalopods have symmetrical bodies prominent heads, and tentacles.

Figure 1

The basic structures of animal hearts. Bird and mammal hearts have four chambers (two atria and two ventricles). A frog, which is an amphibian, has a heart with three chambers (one ventricle and two atria), and fish hearts have two chambers (one atrium and one ventricle). An octopus heart system contains three hearts-one main heart $(\mathrm{H} 1)$ pumping blood to the body and two other hearts $(\mathrm{H} 2$ and H3) pumping blood to the gills. $A$, atrium; $V$, ventricle.

\section{HOW MANY HEARTS DO WE HAVE?}

You surely know that humans and giraffes have just one heart, as most animals do-but not all. Octopuses and squids (animals called cephalopods) have three hearts. Two hearts pump blood to the gills to take up oxygen, and the other pumps blood around the body (Figure 1). Worms are also unusual, with five structures called aortic arches acting as basic hearts. The hagfish, sometimes called the slime eel, has one true heart plus three accessory pumps helping the blood to move. Just when you thought you had heard it all, some animals are heartless. Jellyfish, starfish, and even corals manage very well without hearts. Starfish do not even have blood, so this explains why no heart is required. Instead, they use small hair-like structures called cilia to push seawater through their bodies and they extract oxygen from the water.

For Dr. Who fans, the fictional Time Lords have two hearts, but real humans very rarely do. In extremely unusual cases, people with the disease cardiomyopathy have a second heart attached onto their own heart by doctors. The healthy and damaged hearts work together to share the load. Also, twins that are born connected to each other (conjoined twins) can have two hearts naturally.

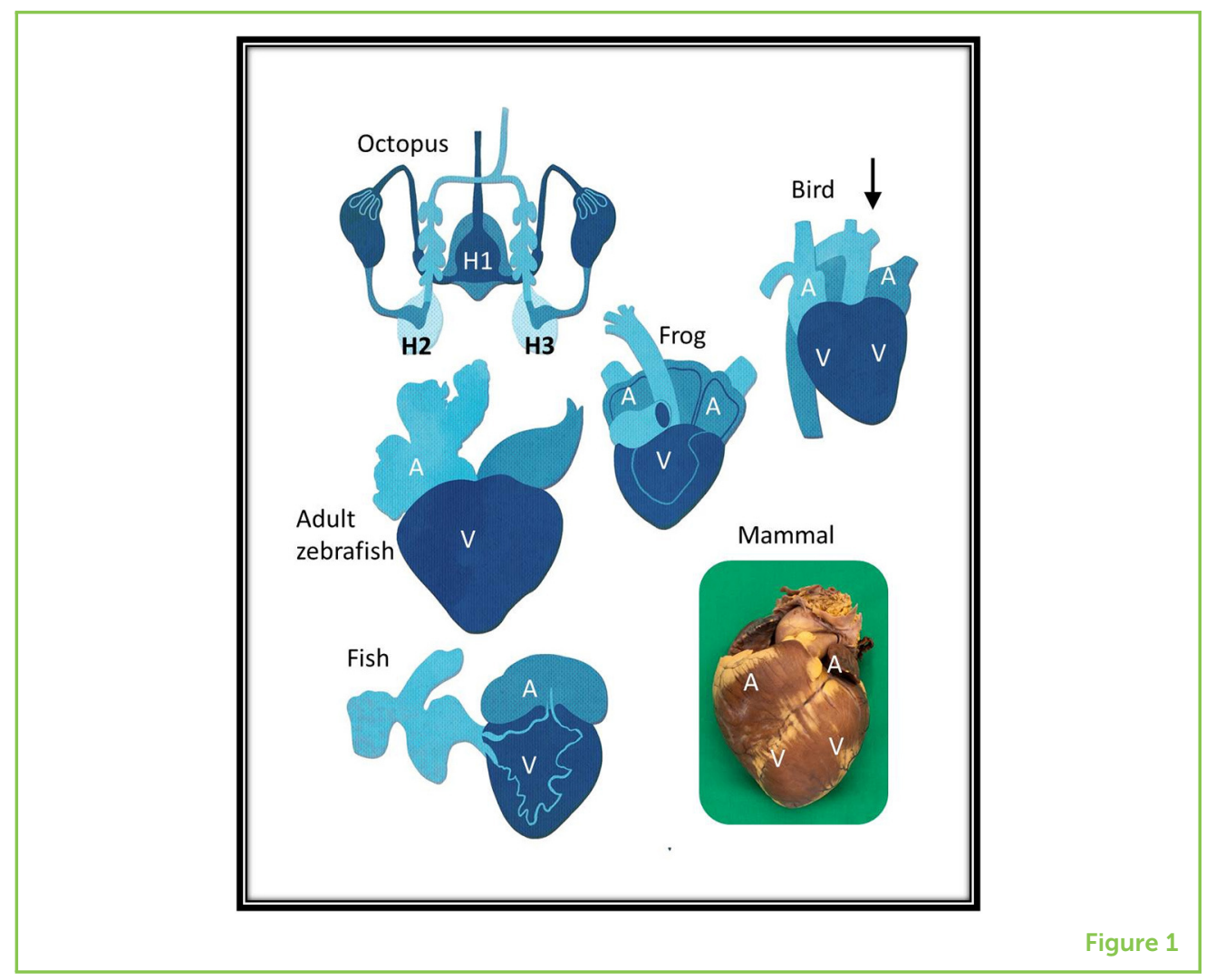


Figure 2

Hearts have adapted differently to best suit every animal. (A) The giraffe has a very large left ventricle so that the heart muscle can pump blood to the body and all the way up the long neck to the head. The giraffe's right ventricle is smaller, as it only pumps blood to the lungs. Microscope images of the heart muscle of a chick (B) and a dog (C) are also shown. The chick is young and therefore only has one ventricle and one atrium. Later, the chick heart will become four-chambered, with two atria and two ventricles.

1 See the paper "Blood Vessels Under the Microscope" for information about blood [1].

\section{ATRIUM}

The upper chamber or chambers of the heart. The plural is atria: for example, you can have one atrium or two atria.

\section{VENTRICLE}

The lower chamber or chambers of the heart.

\section{AMPHIBIAN}

Animals with backbones that need water or wet environments to survive. Amphibians include toads, frogs, salamanders, and caecilians (amphibians without legs or limbs).

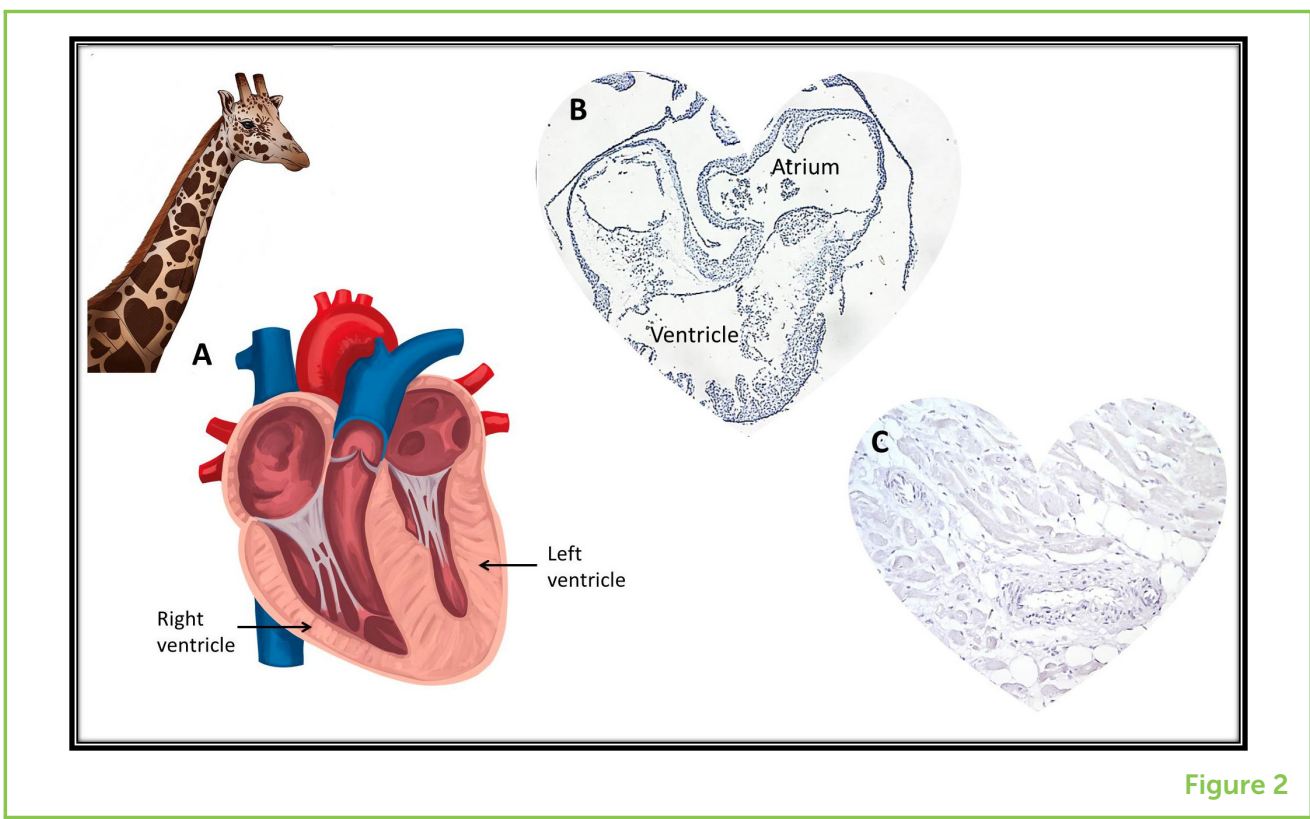

\section{MAMMAL AND BIRD HEARTS}

It is not just the number of hearts that can change between species. The basic structure of this vital organ can be extremely different from one species to the next. Hearts mostly consist of muscle that contracts and relaxes, causing blood to move through blood vessels to and from the lungs and around the body (Figure 2$)^{1}$. As mammals, we have four main parts to the heart, a left and a right atrium and a left and a right ventricle. This is called a four-chambered heart. Other mammals and birds all have four-chambered hearts. Other animal groups, such as reptiles, amphibians, fish, and insects, have hearts that look a little different (Figure 1).

\section{REPTILE AND DINOSAUR HEARTS}

Reptile hearts have three chambers, two atria and one ventricle (Figure 1). The exception is crocodilians, which have four-chambered hearts, just like mammals and birds. However, there is a hole in the crocodile chamber wall, so whether there are three or four heart chambers is up for debate. People often wonder whether dinosaurs evolved from birds or reptiles. Finding a dinosaur heart is very rare because, unlike bone, the heart is a soft tissue, so it is not often preserved. One potentially fossilized heart appeared to show that dinosaurs had four heart chambers, more like birds than reptiles. Sadly, as this specimen was investigated further using more advanced scientific technology, it was found not to be dinosaur tissue, so we still do not know enough about dinosaur hearts to predict which animals dinosaurs evolved from [2]. 


\section{HEMOLYMPH}

Fluid, similar to blood, that some simple animals have to move nutrients and oxygen around their bodies.

\section{HEART RATE}

The number of times per minute that a heart beats.

\section{AMPHIBIAN HEARTS}

Amphibians are an interesting group, as their hearts vary greatly. Living on land and in water, many get oxygen using their lungs, but also take it up via their skin. Most amphibians, including frogs and toads, have three-chambered hearts, with two atria and one ventricle (Figure 1). However, lungless salamanders do not have a structure called a septum to divide the atrium into two separate parts, so this animal has just one atrium and one ventricle. Some lesser known amphibians seem to have a septum in between their ventricles, so perhaps ancient amphibians had four-chambered hearts, like mammals and birds.

\section{FISH AND INSECT HEARTS}

Fish hearts have just two chambers, an atrium and a ventricle (Figure 1). Insects often have just a tube that pumps hemolymph (the name for the insect equivalent of blood) freely around the entire body, with a vessel to help it move. Cockroaches, however, have 13 heart chambers!

\section{HOW BIG IS YOUR HEART?}

It goes without saying that heart size varies in different animals. After all, a whale could not survive with a mouse-sized heart. An adult human heart weighs about $0.6 \mathrm{lbs}$. If you make a fist, that is roughly the size of your heart. The giraffe heart is a hefty 26 lbs, but the blue whale really tips the scales at 400 lbs. The world's smallest heart belongs to the fairyfly. This tiny animal is just $0.2 \mathrm{~mm}$ long, and a microscope is needed to see its heart.

Hearts are normally about $0.6 \%$ of an animal's body mass. Dogs and wolves have relatively large hearts in comparison with their weight, at $0.8 \%$. Meanwhile, the cat heart is just $0.35 \%$ of a cat's body weight. Hopefully, relative heart size and the amount of love animals feel are not related. If they were, the world's smallest mammal, the Etruscan shrew, would have a lot of love to give! The mouse-like shrew weighs a tiny $2 \mathrm{~g}$ and is around $4 \mathrm{~cm}$ long, but its heart makes up $1.2 \%$ of its body weight [3]. Scientists also found that the shrew heart can shrink in cold weather. This shrinkage helps shrews survive harsh climates, by reducing the amount of food it needs. This little mammal eats twice its body weight in food every day, so hibernation is not an option. They rarely even sleep.

\section{SWIFT AND SLUGGISH HEART RATES}

The way animals' hearts work varies between species, too. The heart rate, measured in beats per minute (bpm), varies in different species. 


\section{VIDEO 1}

Early on, when a chick is growing in an egg, its heart can be seen on the outside of its body. Over time, the heart will move inside the body. This video shows a chick's heart beating when it is just a few days old. The heart is still a tube containing two chambers, a ventricle and an atrium, but as it grows it will eventually have four chambers. You can see the blood pumping through the heart chambers.
Generally, larger animals have slower heart rates. A large slug has a heart rate of around $55 \mathrm{bpm}$, while smaller slug species are in the 90s. Many whales have heart rates of 10-30 bpm, giraffes are 40-90, and cats are around 150. In even smaller animals, the number increases: an adult chicken has a heart rate of 259 bpm, a chick is 400 (Video 1), and the hamster heart beats away at $450 \mathrm{bpm}$. The little Etruscan shrew clocks 835 bpm, more than 12 times higher than a person. The highest recorded shrew rate was 1,511 bpm, a world record for a warm-blooded animal [3].

People have heart rates of around 60-100 bpm, but children often have slightly higher rates. At 1 month old, 70-190 is fairly normal, 80-120 for 3-4-years-olds, and 60-100 by the time a child is 10 years old. A growing baby inside its mother starts at $80 \mathrm{bpm}$ in week 5, 155-195 at 9 weeks old, and around 130 just before it is born. Interestingly, the human heart starts as a tube in the 19-20-days-old embryo, rather like a fish, but gradually rotates, develops, and separates into four chambers over the next 6 weeks.

\section{EXERCISE, TEMPERATURE AND HIBERNATION ALL CHANGE HEART RATE}

Heart rate changes in most exercising animals. Running giraffes can reach 170 bpm and humans can hit 220, but ideally it should be a little less. A crocodile heart rate at $10^{\circ} \mathrm{C}$ is $1-8 \mathrm{bpm}$, at $28^{\circ} \mathrm{C}$ it hits 24-40, and once it reaches over $40^{\circ} \mathrm{C}$, the heart can become damaged. Young swifts (birds) lower their heart rates when in the nest, to avoid starvation. Hibernating animals can also lower their heart rates. Grizzly bears normally clock 84 bpm, which lowers to 19 bpm during hibernation; a human heart would usually stop working if it went that low. Emotions, such as fear, love, and excitement, as well as hormone levels, sickness, oxygen levels, and other factors both inside and outside of the body can change the heart rate.

\section{MENDING A BROKEN HEART}

In our previous Frontiers for Young Minds paper "Mending a Broken Heart," we looked at fixing failing hearts $[4,5]$. The zebrafish has a very important ability: it can regenerate (regrow), so if it gets injured or its heart has a problem, it can often repair itself. Human bodies are fantastic, and they continuously try to replace heart cells and repair heart tissue, but the zebrafish is a real professional at mending a broken heart.

\section{CONCLUSIONS}

In this article, we looked at some of the similarities and differences between the hearts of various species. Mammals and birds have 
very similar hearts due to evolution, while reptiles, fish, insects, and other animals evolved hearts that are slightly differently from those of mammals. The environment both inside and outside of each animal helps control the heart's structure and function, but lifestyle choices, such as exercise and food, can have huge impacts on your heart's health. Your friends' hearts are more similar to yours than to a giraffe's for example, and even more similar than to a frog or spider heart, but every person's heart is unique. Your heart is constantly adapting to the situations you are in, reacting to food, exercise, emotions, and illness. Unlike a squid, you only have one heart, and it will beat around 2.21 billion times in your life, so it is worth keeping it healthy.

\section{ACKNOWLEDGMENTS}

The authors would like to thank our young reviewers, Erin and Joshua Rutland. Part of this work was made possible due to funding from the Anatomical Society with a Public Engagement and Outreach grant to Catrin titled Anatomy for ALL-Making Anatomy Accessible. We would also like to thank the British Science Association and University of Nottingham for awarding Catrin with a BSA Media Fellowship 2019.

\section{REFERENCES}

1. Machado, M., Mitchell, C., Franklin, J., Thorpe, A., and Rutland, C. S. 2020. Blood vessels under the microscope. Front. Young Minds 8:151. doi: 10.3389/frym.20 19.00151

2. Cleland, T., Stoskopf, M., and Schweitzer, M. 2011. Histological, chemical, and morphological reexamination of the "heart" of a small Late Cretaceous Thescelosaurus. Naturwissenschaften. 98, 203-211. doi: 10.1007/s00114-0100760-1

3. Jurgens, K. D., Fons, R., Peters, T., and Sender, S. 1996. Heart and respiratory rates and their significance for convective oxygen transport rates in the smallest mammal, the Etruscan shrew Suncus etruscus. J. Exp. Biol. 199:2579-84.

4. Clark, N., Alibhai, A., and Rutland, C. S. 2018. Mending a broken heart-the genetics of heart disease. Front. Young Minds 6:19. doi: 10.3389/frym.20 18.00019

5. Simpson, S., Rutland, P., and Rutland, C. S. 2017. Genomic insights into cardiomyopathies: a comparative cross-species review. Vet. Sci. 4:19. doi: $10.3390 /$ vetsci4010019

SUBMITTED: 04 March 2020; ACCEPTED: 21 August 2020; PUBLISHED ONLINE: 02 October 2020.

EDITED BY: Vitor Engracia Valenti, São Paulo State University, Brazil

CITATION: Alibhai A, Stanford K, Rutland S and Rutland CS (2020) Hearts, and the Heartless, in the Animal Kingdom. Front. Young Minds 8:540440. doi: 10.3389/frym. 2020.540440 

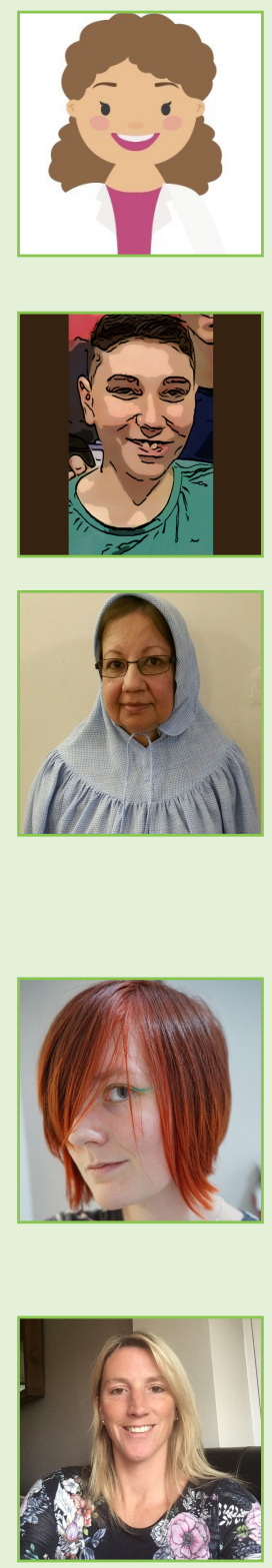

CONFLICT OF INTEREST: The authors declare that the research was conducted in the absence of any commercial or financial relationships that could be construed as a potential conflict of interest.

COPYRIGHT @ 2020 Alibhai, Stanford, Rutland and Rutland. This is an open-access article distributed under the terms of the Creative Commons Attribution License (CC BY). The use, distribution or reproduction in other forums is permitted, provided the original author(s) and the copyright owner(s) are credited and that the original publication in this journal is cited, in accordance with accepted academic practice. No use, distribution or reproduction is permitted which does not comply with these terms.

\section{YOUNG REVIEWERS}

\section{BRUNA, AGE: 15}

$\mathrm{Hi}$, my name is Bruna and I live in São Paulo.

NÍCOLAS, AGE: 11

Cheerful boy who loves to play basketball and be with his family.

\section{AUTHORS}

\section{AZIZA ALIBHAI}

I am a research scientist at The University of Nottingham. My main area of research is cardiovascular biology and I help teach university students to become veterinary surgeons and scientists. When I am not working, I carry out a lot of community and charity work and love spending time with my family, including my two grandchildren. I have three children. The youngest has just finished school and the older two have completed their degrees at university.

\section{KELLY STANFORD}

I am a Manchester-based science communicator and artist currently researching how art and games can be used as tools for science outreach, as part of a M.Sc. at the University of Hull. I have worked in collaboration with researchers all over the world, creating interdisciplinary projects that are used to communicate science to the public and to inspire people to get involved in STEM.

\section{SHARON RUTLAND}

I am a teacher and have taught young people for over 20 years. I am also a professional proofreader and copy-editor and more recently I have written my first children's novel. I have two children, Joshua and Erin, who love learning about animals and science. In my spare time, I enjoy playing tennis to keep my heart fit and healthy and my passion for the theater and acting keeps my heart racing, especially on opening night. 


\section{CATRIN SIAN RUTLAND}

I am an Associate Professor of Anatomy and Developmental Genetics at The University of Nottingham and a 2019 British Science Association Media Fellow. I lead a group of research scientists investigating why people and animals suffer from heart and blood vessel disorders, looking for techniques to detect, prevent, and cure. When I am not working, I love to travel around the world, visit museums, and write science fiction. My boyfriend Andrew and I go running to keep our hearts healthy. ${ }^{*}$ catrin.rutland@anottingham.ac.uk 